\title{
Demanda espontânea e planejamento estratégico situacional no Programa Saúde da Família de Pindamonhangaba
}

\author{
Spontaneous demand and Situational Strategic Planning in the Family Health
} Program of Pindamonhangaba, São Paulo, Brazil Demanda espontánea y planeamiento estratégico in situ en el Programa Salud de la Familia de Pindamonhangaba, São Paulo, Brasil

Milena Lopes Santana ${ }^{1 *}$

\begin{abstract}
Palavras-chave: Planejamento Estratégico Programa Saúde da Família Acolhimento
\end{abstract}

Keywords: Strategic Planning Family Health Program User Embracement

\section{Resumo}

A partir de pesquisa qualitativa embasada na triangulação de métodos, objetivou-se avaliar a percepção de gerentes, técnicos e usuários de quatro unidades de saúde da família de Pindamonhangaba (SP), quanto à condução da demanda espontânea, no intuito de averiguar se ela está contemplada no Planejamento Estratégico Situacional. Foram encontradas as seguintes estruturas de análise relacionadas à condução da demanda espontânea: acolhimento, processo de trabalho, registros, prioridades, planos, comunicação e educação permanente. Os momentos explicativo, normativo, estratégico e operacional foram os temas pertinentes ao planejamento estratégico. A análise das falas sugere que o processo de trabalho é fragmentado, hierarquizado e centrado no enfermeiro. As prioridades de atendimento não se dão por meio de critérios técnicos, mas pelo senso comum, o que resulta no descontentamento do usuário e na oferta de assistência de baixa qualidade. Os profissionais envolvidos não promovem processo comunicativo capaz de uniformizar a linguagem, útil na elaboração de um objetivo comum. Não há, portanto, sinergia da equipe para 0 alcance de melhores formas de se conduzir a demanda espontânea, as quais resultam de um plano mental, da "tentativa e erro" e da experiência cotidiana, em detrimento de um pensamento estratégico. 0 estudo revela que o atual modelo de gestão deve ser revisto, sob o risco de comprometer o desenvolvimento 'sócio regional, e propõe a implantação de educação permanente para os trabalhadores de saúde do município, com ênfase no planejamento estratégico, na apropriação e reinterpretação das características do território e situações vivenciadas.

\section{Abstract}

From a qualitative research based on a method triangulation, this paper focused on evaluating the perception of managers, technicians and users of four Primary Care Health Centers of Pindamonhangaba, São Paulo, Brazil, as to the spontaneous demand conduct, in order to analyze if they have been pondered on the Situational Strategic Planning. The following analysis structures were found related to the spontaneous demand conduction: user embracement, work process, records, priorities, plans, communication and permanent education. The explanative, normative, strategic and operational moments were the themes pertinent to the strategic planning. The speech analysis suggests that the work process is fragmented, hierarchical and focused on the nurse. The assistance priorities do not occur by means of technical criteria, but by common sense, which results in a discontented user and in a poor quality assistance. The professionals involved do not promote a communicative process able to unify the language, useful in the elaboration of a common aim. There is not, therefore, a team synergy to achieve the best ways of conducting the spontaneous demand, which result from a mental plan, from "attempt and failure" and from everyday

\footnotetext{
Prefeitura Municipal de Pindamonhangaba. São Paulo (SP), Brasil. milenalopessantana@gmail.com

*Autor para correspondência

Fonte de financiamento: nenhuma.

Conflito de interesses: declarou não haver.

Recebido em: 24/11/2010

Aprovado em: 05/04/2011
} 
experience, to the detriment of a strategic thought. The study reveals that the present management model needs to be reviewed, under the risk of compromising the social regional development and it proposes the permanent education implantation to the health workers in the municipality, emphasizing the strategic planning, the appropriation and reinterpretation of the territory features and experienced situations.

\begin{abstract}
Palabras clave:
Planificación Estratégica Programa de Salud Familiar Acogimiento
\end{abstract}

\section{Resumen}

A partir de la investigación cualitativa basada en la triangulación de los métodos, se decidió evaluar la percepción de gerentes, técnicos y usuarios de cuatro unidades de salud familiar de Pindamonhangaba (en São Paulo), con respecto a la conducción de la demanda espontánea, con el objetivo de averiguar si la misma está contemplada en el planeamiento estratégico in situ. Fueron encontradas las siguientes estructuras de análisis relacionadas a la conducción de la demanda espontánea: acogimiento, proceso de trabajo, registros, prioridades, planes, comunicación y educación permanente. Los momentos explicativo, normativo, estratégico y operacional fueron los temas pertinentes al planeamiento estratégico. El análisis de los discursos sugiere que el proceso de trabajo es fragmentado, jerarquizado y focalizado en el enfermero. Las prioridades de la atención no ocurren a través de criterios técnicos, sino por el sentido común, lo que da como resultado la insatisfacción del usuario y la asistencia de baja calidad. Los profesionales involucrados no establecen un proceso comunicativo que sea capaz de unificar el lenguaje útil en el desarrollo de un objetivo común. № existe, por lo tanto, sinergia en el grupo para el alcance de mejores formas de saber llevar la demanda espontánea, que resultan de un plan mental, de "ensayo y error" y de la experiencia cotidiana, en detrimento de un pensamiento estratégico. El estudio revela que el actual modelo de gestión necesita ser revisado, con el riego de comprometer el desarrollo social de la región, y propone la implementación de la educación permanente a los trabajadores de la salud del municipio, con énfasis en el planeamiento estratégico, en la apropiación y reinterpretación de las características del territorio y situaciones vividas.

\section{Introdução}

O acolhimento é compreendido de forma diferente por diversos autores. Nem sempre as colocações são divergentes, mas complementares ${ }^{1,2}$. É visto como um dos instrumentos que compõem o processo de trabalho em saúde ${ }^{3}$, sendo fundamental para operacionalizar a acessibilidade da clientela ${ }^{1}$. Sob outro aspecto não caberia ao acolhimento apenas a função de acesso à demanda espontânea, mas o de aceitação do doente como sujeito de direitos, desejos para os quais se tornam necessários uma boa comunicação e relacionamento profissional-paciente, a fim de estabelecer uma relação de compromisso e de confiança mútua ${ }^{2}$, ainda que, muitas vezes, resume-se a uma prática centrada na queixa clínica, levando a uma consulta nos modelos tradicionais 4 .

Neste estudo, entende-se por acolhimento não apenas a forma humanizada, respeitosa e comprometida que deve estar presente na relação profissional-usuário, mas também um recurso para se garantir o acesso ao serviço de saúde pela população, tendo em vista que muitos trabalhadores denominam acolhimento como demanda espontânea do usuário à unidade.

Realizou-se este trabalho, pois, empiricamente, observaram-se formas semelhantes no que se refere à condução da demanda espontânea nas Unidades de Saúde da Família do município de Pindamonhangaba (SP), apesar das diversidades locais evidenciadas nos processos de territorialização e perfis socioambientais e epidemiológicos.

Passou-se a questionar se diferentes modos de gerenciar um local poderiam facilitar ou dificultar o acesso à população, tendo em vista que a gerência de uma unidade pode ser peça fundamental na transformação do processo de trabalho ${ }^{5}$ e o fato de alguns autores acreditarem na potencialidade do acolhimento para reorganizar os serviços de saúde $e^{6,7}$, apesar das dificuldades apontadas na literatura: falta de recursos humanos para operacionalizá-lo, excesso de demanda, falta de interesse dos profissionais, falta de articulação da equipe, postura não acolhedora, sobrecarga do trabalho do enfermeiro, manutenção do modelo médico-centrado e resolutividade inferior à esperada 5 .

No planejamento dos serviços de saúde, o Planejamento Estratégico Situacional $(\mathrm{PES})^{8}$ é uma ferramenta que deve ser incorporada pela equipe que trabalha no Programa Saúde da Família (PSF) e utilizada no gerenciamento dos serviços de saúde ${ }^{9}$ como um método de resolução de problemas detectados na realidade, confrontados com um padrão considerado não adequado ou não tolerável e que motivam os atores sociais a enfrentá-los ${ }^{10}$. De modo geral, o planejamento contribui para a identificação de potencialidades e fragilidades na implementação da Atenção Básica, além de favorecer a construção de intervenções positivas nesse acompanhamento, voltadas para melhorias do cuidado e da gestão ${ }^{11}$.

Neste estudo, objetivou-se, portanto, avaliar a percepção dos atores sociais do PSF do município de Pindamonhangaba quanto à demanda espontânea, no sentido de verificar se ela está contemplada ou não no PES, considerado uma ferramenta gerencial. Foram dois os pressupostos: a utilização do PES pelos gestores levaria a uma resposta eficaz na condução da demanda espontânea e sua não utilização poderia levar a um resultado insatisfatório e ineficaz na condução dessa demanda, ainda que outras estratégias fossem utilizadas. 


\section{Método}

Realizou-se pesquisa qualitativa, exploratória, nos moldes de estudo de casos múltiplos.

Por meio da "triangulação de métodos" 12 , a fala de gerentes, técnicos (enfermeiros e auxiliares de enfermagem) e usuários, pertencentes a quatro Unidades de Saúde da Família de Pindamonhangaba pôde ser triangulada, interpretada e analisada. Essa técnica ${ }^{12}$ envolve um processo sistemático de fazer perguntas sobre um determinado assunto considerado relevante e um método de avaliação de programas ou projetos sociais. De fato, a avaliação por triangulação de métodos constitui um "tercius", na medida em que os avaliadores não são quem formula e nem quem demanda. No processo, tanto os formuladores e os beneficiários como os gestores e os técnicos são chamados a se autoavaliar ${ }^{12}$. Assim, os atores do PSF - como é o caso - não são os objetos do estudo, mas os sujeitos que se relacionam e têm uma visão particular do cenário em que estão envolvidos ${ }^{13}$.

Este estudo encontra-se dentro dos preceitos éticos da Resolução 196 e foi aprovado pelo Comitê de Ética da Universidade de Taubaté, UNITAU (Protocolo nº.0173/07).

Todas as entrevistas daqueles que se permitiram fazer parte do mesmo foram gravadas pela pesquisadora sob a autorização do pesquisado, firmando-se entre as partes que o conteúdo gravado seria utilizado apenas com fins científicos, conforme consentimento livre e esclarecido.

Cada entrevista realizada foi contextualizada, criticada, comparada e triangulada com outras ${ }^{14}$. Os atores das Unidades de Saúde da Família (USF) não foram compreendidos como objetos de estudo, mas sujeitos que se relacionam e têm uma visão particular do cenário em que estão envolvidos $^{14}$. Para cada ator social entrevistado perguntou-se inicialmente "como é o acolhimento em sua unidade?" e, na medida em que o discurso foi acontecendo, conforme a abertura da pessoa, outros assuntos foram sendo inseridos no decorrer da entrevista.

Estruturas de análise puderam ser elaboradas a partir de temas semelhantes encontrados nos discursos dos diversos atores sociais ${ }^{14}$. Foi possível classificar o conjunto de depoimentos a partir dos atores (gerentes, técnicos e usuários) ou dos grupos (cada uma das quatro unidades de saúde); esses agrupamentos podem coexistir, compondo subcategorias dentro de categorias ${ }^{14}$.

Com a construção das estruturas de análise concluída, seguiram-se três etapas ${ }^{8,14}$ :

1. descrição, na qual os dados são apresentados de forma que as "opiniões dos diferentes informantes sejam preservadas da maneira mais fiel possível" ${ }^{8,14}$;
2. interpretação: sua meta é a "busca de sentidos das falas e das ações para alcançar a compreensão ou explicação para além dos limites do que é descrito" ${ }^{8,14}$. É o ponto de partida, uma vez que o trabalho inicia-se com as próprias interpretações dos atores e o ponto de chegada, já que, nessa fase, interpretam-se essas interpretações. Nessa fase, além da leitura compreensiva do material selecionado, é fundamental usar conceitos ou referenciais teóricos e contextualizações que orientem o olhar sobre os dados ${ }^{14}$;

3. a análise é a etapa na qual se propõe ir além, expandir o que é descrito, por meio da decomposição de um conjunto de dados. O processo analítico se dá pela "busca das relações entre as partes" ${ }^{\prime, 14}$ que compõem esse conjunto de dados.

Neste estudo, propõe-se fazer uma análise temática, ou seja, reúnem-se categorias comuns entre as falas dos atores sociais em temas (estruturas de análise), considerados o ponto de partida para as interpretações e a análise propriamente dita.

Alguns autores propõem a construção de inferências ${ }^{8,15}$, em que o pesquisador busca as ideias que estão por trás do texto, a partir das estruturas de análise ${ }^{8}$. Elas também podem ser construídas a partir de perguntas tais como: "o que conduziu o entrevistado a emitir determinado enunciado?"; "que conseqüências esse enunciado pode provocar?"15.

Tendo em vista as questões apontadas nesse item, segue o modo como os resultados foram apresentados e a discussão dos mesmos, buscando revelar se os modelos de gestão do PSF precisam ser repensados.

\section{Resultados}

Os temas mais comuns encontrados nos discursos dos entrevistados podem ser identificados no Quadro 1. Cada estrutura de análise possui subtemas, ou seja, categorias relevantes que evidenciam a percepção dos atores sociais sobre o enfrentamento de cada um no que diz respeito à condução da demanda espontânea.

O acolhimento, o processo de trabalho nos serviços de saúde, os diversos modos de se priorizar e registrar ações de saúde, o processo comunicativo nas unidades de saúde, a educação permanente da equipe multiprofissional e a construção de planos de operacionalização são exemplos dos temas discorridos nas entrevistas, no intuito de evidenciar a percepção dos atores sociais quanto à demanda espontânea ${ }^{16}$.

O Quadro 2 revela as estruturas de análise e categorias relacionadas ao PES, composto de quatro momentos ${ }^{17,18}$ : 
Quadro 1. Estruturas de análise e categorias relacionadas à condução da demanda espontânea, encontradas nos discursos dos atores sociais.

\begin{tabular}{|lll|}
\hline Acolhimento & Processo de trabalho & Prioridades \\
\hline $\begin{array}{l}\text { Função, sentido e significado do acolhimento } \\
\text { designado pelos atores sociais }\end{array}$ & Organização do trabalho & Identificação das demandas \\
Responsável pelo acolhimento na unidade & Processo de trabalho & Estabelecimento de prioridades de atendimento por ator social \\
\hline Planos & Problemas encontrados & \\
\hline Identificação dos planos traçados & Registros & Comunicação \\
Ator social responsável pela elaboração dos planos & Formas de registro de dados e/ou informação & Processo comunicativo estabelecido na unidade e entre os atores \\
Compreensão dos planos por ator social & SIAB & Qualidade do processo comunicativo \\
& Capacitação & \\
\hline
\end{tabular}

Quadro 2. Estruturas de análise e categorias relacionadas ao Planejamento Estratégico Situacional.

\begin{tabular}{|lccc|}
\hline Momento explicativo & Momento normativo & Momento estratégico & Momento operacional \\
\hline Diagnóstico situacional & Formulação de objetivos & Viabilidade dos planos & Execução dos planos \\
Identificação de problemas & Prazo para executá-los & Avaliação dos atores & Avaliação de mudanças \\
Estabelecimento de prioridades & & & \\
\hline
\end{tabular}

1. momento explicativo: os problemas são identificados e explicados de forma situacional e hierarquizada;

2. momento normativo: por meio dele, traçam-se os objetivos a serem alcançados a curto, médio e longo prazo com base na análise dos problemas identificados e nas prioridades estabelecidas;

3. momento estratégico: o momento do "pode ser" e do "como fazer", pois inclui a formulação de uma estratégia e a análise de viabilidade em três níveis (viabilidade política, econômica e institucional-organizativa);

4. momento tático operacional: corresponde à programação de curto prazo e inclui a tomada de decisão, controle e avaliação.

Fragmentando o Quadro 2 e adicionando os discursos dos atores sociais entrevistados, por unidade e de forma triangular, obtém-se o Quadro 3, que procura evidenciar a relação entre a Demanda Espontânea e o PES, com o propósito de verificar se aquela está contemplada ou não neste, considerado uma ferramenta gerencial ${ }^{16}$.

\section{Discussão}

\section{Prioridades}

Dentro da assistência oferecida, as falas revelam três prioridades básicas.

$\mathrm{Na}$ primeira, o critério é por grupo populacional ou por ciclo de vida, ou seja, atendem-se prioritariamente crianças, gestantes e idosos. Essa ideia é mencionada no documento redigido pelo Ministério da Saúde em $2006^{19}$. Sobre esse modo de as unidades estabelecerem prioridades de atendimento, vale mencionar que ele é construído
Quadro 3. Estruturas de análise e categorias relacionadas à relação entre a Demanda Espontânea e o Planejamento Estratégico Situacional, encontradas nos discursos dos atores sociais.

\begin{tabular}{l} 
Momento explicativo \\
\hline Atendimento das ocorrências e intercorrências \\
Disponibilidade para acolhimento \\
Agendamento de horário para atendimento médico das intercorrências \\
\hline Momento normativo \\
Registro de dados \\
Ausência de procedimentos normativos \\
\hline Momento estratégico \\
\hline Discussão de problemas \\
Elaboração de estratégias \\
Decisões burocratizadas \\
Ações e decisões isoladas \\
\hline Momento operacional \\
\hline Modo de execução das ações \\
Qualidade das mudanças ocorridas \\
Percepção das mudanças
\end{tabular}

a partir de normas legais, não por avaliação sistemática da realidade local.

A segunda prioridade refere-se ao profissional ser a prioridade ("paciente pro acolhimento é uma coisa que dava pra esperar numa consulta geral”; "o balcão, pra se livrar do piti, jogava pra gente”), em detrimento da ótica centrada no usuário.

$\mathrm{O}$ critério em que o acesso à consulta médica é a prioridade é muito utilizado pelos usuários quando é grande a dificuldade de marcação da mesma ou, melhor dizendo, quando existe demanda reprimida na unidade.

Poucas falas envolvem técnicos que ressaltem o critério clínico para o estabelecimento das prioridades assistenciais 
e individuais (causa evidente, objetiva e circunstancial, como dor, hipertensão, hiperglicemia e febre). Mesmo nas unidades que recebem o paciente nessas condições, o fazem com hora marcada, ou seja existe um horário determinado em que essas pessoas são atendidas pelo médico, independentemente de gravidade. É o horário destinado às intercorrências, aos encaixes ("de 7:30 às 8:30 essas intercorrências: se tiver febre e dor”) e, via de regra, há um certo número de vagas para o período. Se, por alguma razão, o número de pacientes ultrapassar a quantidade de vagas, ainda que a gravidade do problema exigir atendimento, é comum o encaminhamento a uma unidade de pronto atendimento.

Quando se percebe uma condição em que a clínica exija o atendimento de um usuário prioritariamente a outro, esse critério é desvalorizado, ou entendido como salvaguardado pela oferta de um horário específico para o atendimento. É o senso comum e não o senso crítico que delimita o processo de trabalho, desvalorizando qualquer pressuposto teórico de planejamento estratégico.

\section{Planos}

Os planos podem ter maiores chances de sucesso em sua realização se todas as unidades reservarem um momento para que as equipes repensem sua forma de atendimento e os critérios estabelecidos para o mesmo, principalmente no que trata a condução da demanda espontânea, tendo em vista que os resultados obtidos não evidenciam a elaboração de planos estratégicos que garantam resultados satisfatórios.

A realidade é que não há estruturação de um pensamento estratégico ${ }^{20}$ por parte do gerente ("não se faz planejamento, acho que não tem") e, consequentemente, pelo restante da equipe (ideias ..."chegou lá de cima"). Via de regra, o plano é mental ${ }^{21}$ e o senso comum decide o que irá permanecer ou ser alterado no processo de trabalho. A ideia que aparentemente dá certo se mantém, e a que dá errado é modificada repetitivamente, sem consciência crítica, até parecer adequada ("a idéia partiu de várias tentativas: assim dá, assim não dá”).

As falas de alguns atores sociais não apontam para um planejamento estratégico que garanta planos capazes de resolver os problemas prioritários, mesmo porque não há consenso e participação efetiva entre os membros desta unidade.

Geralmente, são poucos os fatores que auxiliam e, mais que tudo, motivam os profissionais a pensar em algum tipo de plano capaz de reverter situações indesejadas.

Este cenário contraria, portanto, a proposta de que os planos sejam elaborados de forma estratégica, tendo em vis- ta que são definidos sem qualquer procedimento técnico, e realizados apenas para o cumprimento de normas técnicas.

\section{Registro das informações}

O Ministério da Saúde enfatiza a utilização de algum sistema de informação escrita que auxilie o gerente no processamento de informações para o devido monitoramento das ações realizadas no serviço e a avaliação necessária dos indicadores de qualidade da assistência prestada ao usuário ${ }^{22}$.

Produzir e analisar informações é suporte básico para a tomada de decisão racional e eficiente ${ }^{23}$; contudo, as falas apontam que técnicos e gerentes não valorizam o Sistema de Informação de Atenção Básica (SIAB) como um recurso para planejar ações de saúde ${ }^{24}$ ("trabalho a esmo"; "não está sendo utilizado"; "falta dados"; "o SIAB é complicado").

Até o momento, as informações produzidas pelos atores sociais das unidades do estudo são registradas ("todos os atos são registrados, ter a quantidade"; "vai mostrar realmente o quanto a gente trabalha"; "pra mostrar pra equipe que o trabalho dela está dando certo, é uma forma de avaliar"; "a gente vai discutir com a pessoa da área qual o motivo, uma justificativa"), mas não são submetidas a procedimentos técnicos de avaliação, o que não inviabiliza apenas a percepção do que precisa ser modificado e, consequentemente, a confecção de objetivos pertinentes ao mesmo, como também a transmissão correta dessas informações.

\section{Processo comunicativo}

A comunicação eficaz não pode ser obtida quando o gerente tende a centralizar as informações nele próprio, porque torna frágil a participação da equipe, princípio fundamental da gestão participativa ${ }^{25}$, por meio da qual mudanças podem ser realizadas.

Em certas unidades, os técnicos não se sentem fazendo parte do processo de tomada de decisões, o que leva à abertura para uma comunicação ineficaz. O processo comunicativo não é formalizado e estabelecido de forma participativa, então não há garantia de envolvimento e compromisso de todos os profissionais no que se refere às ações de saúde e à orientação correta aos usuários ("cada um falando uma língua, então fica conflitoso você dar uma informação pro paciente").

Por outro lado, na unidade em que se estabelece um canal de comunicação participativo, não há indícios de que esse fluxo tenha sido elaborado formalmente, por meio de um planejamento. Foi o bom relacionamento entre os in- 
tegrantes da equipe, ou seja, a informalidade, acrescido do perfil do gerente (gerenciamento descentralizado), do espaço garantido pelas reuniões semanais, pelo porte da unidade (equipe mínima) e o tamanho relativamente pequeno de usuários referenciados, que, em conjunto, favoreceram um processo comunicativo mais qualificado nessa unidade. Contudo, não se pode menosprezar o fato de que esse contexto se reflita no usuário e se reverta em novos modos de cuidar e trabalhar ("a gente sempre conversa na reunião de equipe, até a hierarquia que a gente sabe que tem, mas todo mundo pode falar"; "a gente vai conversar, 'olha, tem horário pra isso' e até colocamos no prontuário que orientamos a mãe das intercorrências").

\section{Educação permanente}

Apesar de nenhuma das unidades promover a capacitação de funcionários de modo formal, cada USF enfocou a necessidade da mesma de modos diferentes: "o ACS não tem capacitação"; "capacitação para os enfermeiros"; "treinamento que levasse eles à reflexão"; "tinha que ter uma reciclagem".

Atores sociais que receberam treinamento mencionaram a capacitação como um recurso que os auxilia na execução de uma assistência de melhor qualidade ${ }^{26}$, já que a capacitação reflete diretamente o desempenho profissional: "quando a gente chegou aqui pra trabalhar como ACS, a gente não tinha muita noção das coisas. A partir dessa capacitação mudou totalmente a cabeça. Era PS, ta mudando pro PSF, então a cabeça dos funcionários era uma e tem que mudar pra outra, ta num momento de transição. Eles não tiveram essa formação que a gente teve. Eu acho que se eles tivesse, melhoraria muito".

Por outro lado, técnicos e gerentes que não demonstraram interesse em educação permanente mantêm um processo de trabalho fragmentado e desconectado da realidade ("no máximo 8:30 é o horário disponível pra essas intercorrências"). Talvez essas atitudes provenientes de um trabalhador "alienado" 27 pudessem ser revertidas com capacitação adequada, uma vez que a educação tem potencial para gerar novos conhecimentos e novas maneiras de trabalhar velhas atividades ${ }^{28}$.

\section{Processo de trabalho}

O acolhimento é uma forma de organizar o processo de trabalho ${ }^{4}$, porque, por meio dele, o usuário pode se orientar quanto ao fluxo de atendimento estabelecido na unidade ("não atenderam e mandaram para o pronto-socorro. Vim pra cá, estou pertinho aqui, né, com dor, né? Devia ser atendido aqui"), além de ter potencial para manter a autonomia dos indivíduos envolvidos ("enfrentar fila é horrível. A gente não tem condição de pagar. Só continuo porque não tem opção") e evitar a fragmentação das ações de saúde ("vai passar primeiro pelo auxiliar de enfermagem, vai passar para a enfermagem, vai ter que passar pelo médico, vai ter que passar pelo pronto-socorro"). Contudo, os discursos acima evidenciam justamente o contrário no que se refere à condução da demanda espontânea.

As unidades de grande porte (compostas de três equipes de PSF e uma equipe matricial), pela intensa divisão do trabalho, sugerem que o acolhimento implantado da forma como está não garante a não segmentação do atendimento ${ }^{29}$.

Para o usuário, os prejuízos são muitos: incerteza de se alcançar o que se deseja (pelo fato do atendimento estar atrelado a inúmeras variáveis), risco de receber uma informação errônea (já que são muitos os emissores), tempo de espera para ser atendido muito maior do que o realmente necessário (uma vez que precisa esperar a disponibilidade de cada um desses profissionais para realizar seu atendimento), diminuição do vínculo e confiança estabelecidos ao longo do tempo com os profissionais de saúde local, entre outros.

Para a resolução desses problemas, a construção de espaços coletivos parece viável, tendo em vista que os conselhos gestores e os grupos colegiados de gestão colaboram para uma gestão mais participativa, em que o interesse de todos tem como ser expresso ${ }^{30}$.

Das unidades pesquisadas, somente uma mantém o conselho gestor funcionando e apresenta certo domínio sobre a realidade local por apresentar os mesmos membros da equipe há sete anos. Contudo, conhecer a comunidade é apenas uma parte do processo de trabalho considerado "estratégico”. Sozinho, esse quesito não garante a melhor condução da demanda espontânea, pois as formas propostas para agendar consulta médica ou estabelecer o fluxo de trabalho não advêm de uma avaliação mais rigorosa dos processos anteriormente instalados.

Estratégias como mudar o agendamento para duas vezes semanais no período da manhã não apenas reduziu o número de faltosos, como também "transmitiu" a sensação ao usuário de que há mais vagas para consulta médica. Na realidade, essa ideia é falsa, pois o número de consultas é, via de regra, o mesmo.

O livre agendamento parece não garantir o acesso do usuário ao serviço; caso contrário, não haveria falas como: "chegava mais cedo pra marcar consulta e não conseguia"; "o médico não ia atender, dizia que não ia ter consulta”. Em situações como essa, o enfermeiro acaba agindo como intermediário entre o usuário e o médico. Essa forma de agir do enfermeiro, 
somada ao sistema de "intercorrências" e/ou encaixes implantados, ora também considerado acolhimento por algumas unidades, acaba gerando um novo modelo de assistência: a enfermeiro-centrado.

Por isso, eventualmente, a forma como a pessoa vive e trabalha não é considerada como sendo desencadeante e/ou condicionante do processo saúde-doença. Corre-se o risco, portanto, de que, influenciados pelo modelo de consulta do médico - devido à alta demanda e à necessidade emergente de resolutividade rápida, além da própria cobrança da população por um pronto atendimento - os enfermeiros deixem de se preocupar com estratégias para prevenir doenças e promover saúde, optando por um atendimento voltado à queixa clínica, reiterando, assim, o modelo médico assistencial ${ }^{3}$.

Dessa forma, o estudo revelou que, nas USF de Pindamonhangaba, a intensa divisão do processo de trabalho, a assistência centrada no enfermeiro, a manutenção de uma rotina de serviço, seja no agendamento de consultas, seja no fluxo pelo qual passa o usuário - do momento em que acessa o serviço até a obtenção (ou não) da assistência solicitada -, há um predomínio das estratégias "tentativa e erro" que, uma vez estabelecidas, repetem-se até se tornarem fixas.

\section{Acolhimento}

As falas relacionadas ao acolhimento sugerem que este é fundamentalmente relacionado ao acesso à demanda espontânea ${ }^{1,4}$. Na maioria das unidades do estudo, não existe um sistema que inclua essa demanda no rol de acompanhamentos de rotina.

Os pacientes têm acesso a um número limitado de vagas e a alta demanda é a principal justificativa das unidades para que somente a queixa imediata seja resolvida. Unidades não expostas ao mesmo problema talvez assim o sejam pela proximidade de um pronto atendimento na região. A demanda elevada prejudica a intervenção preventiva e reforça a prática curativa e, via de regra, é o que acontece em todas as unidades avaliadas ${ }^{31}$.

Quando gerentes e técnicos são questionados sobre a razão do acolhimento, as falas revelam as seguintes percepções: "é chegar em determinado lugar em busca de algo que me satisfaça e essa necessidade seja sanada"; "é a pessoa sair dali com o problema resolvido ou encaminhado"; "damos a informação que ele vem buscar"; "serve para atender a emergência"; "é não liberar sem atendimento"; "é perguntar se tá tudo bem, abrir um sorriso".

Mas, para surpresa, essa não é a percepção de muitos usuários: "não atenderam e mandaram para o pronto-socorro"; "não tem médico, não vai vir, não tem aviso"; "horário de almoço, não nos importa que feche a unidade, mas em caso de emergência atendesse"; "eu não estava vindo consultar mais, porque o atendimento estava muito ruim"; "só continuo porque não tem opção, é o centro de saúde que o médico tem tempo pra examinar as pessoas, mas não toca".

Com um sistema de acolhimento bem sucedido, os resultados dos objetivos propostos seriam alcançados, o fluxo de atendimento poderia ser racionalizado, a demanda ambulatorial no pronto atendimento seria reduzida, o número de pessoas que circulariam desorientadas pela unidade diminuiria, a satisfação do cliente aumentaria e o ambiente de trabalho ficaria mais harmonioso ${ }^{32}$.

Todavia, soma-se a esse cenário o agravante de que a maior parte dos profissionais de saúde envolvidos no acolhimento não é capacitada para tal e o fato de ser truncado o processo comunicativo estabelecido nas unidades, tanto quanto o processo de trabalho ser fragmentado. A consequência provável é, portanto, a inviabilidade do acolhimento como uma estratégia de reversão do modelo assistencial, conforme o esperado pelas premissas básicas do Programa Saúde da Família, ao menos nas unidades de saúde do município de Pindamonhangaba.

\section{Condução da Demanda Espontânea e sua relação com o Planejamento Estratégico Situacional}

O planejamento é um dos recursos mais citados no que se refere ao auxílio do gerente na utilização de indicadores para a tomada de decisões ${ }^{24,33,34}$, uma vez que sem planos não se podem organizar eficientemente os indivíduos e controlar o resultado de suas ações ${ }^{10}$.

$\mathrm{Na}$ área da saúde, a utilização do $\mathrm{PES}^{17}$ é recomendada $^{9,18}$, dentre outras razões, porque no trabalho em equipes do PSF ele leva em conta a inclusão e o controle social, motivo pelo qual o PES pode ser considerado ferramenta gerencial importante 9 .

No momento explicativo do $\mathrm{PES}^{17}$, recomenda-se que os problemas sejam identificados e explicados ${ }^{18}$. Os resultados obtidos sugerem que gerentes, técnicos e usuários percebem, basicamente, o seguinte problema, comum a todas as unidades de saúde: demanda por atendimento maior que a oferta de serviços ("não está tendo vaga"; "vinha marcar consulta, estava muito demorada"; "chega todo dia no posto tá aquela fila enorme").

Se o ponto de partida para um bom planejamento é o diagnóstico da situação, o qual inclui identificar os problemas e priorizá-los de modo que as prioridades possam se tornar planos de ação ${ }^{24}$, há de se ressaltar que as unidades apresentam dificuldade em fazê-lo. Nesses serviços, o sistema 
de priorização é construído a partir de normas técnicas gerais, não de uma avaliação sistemática da realidade local, o que iria garantir critérios mais específicos voltados às peculiaridades de cada unidade.

Muito embora os discursos não tenham dado ênfase a um pensamento estratégico no modo de resolver os problemas, o planejamento é uma atividade inerente ao ser humano ${ }^{21}$. Assim, nas unidades estudadas, é o senso comum e não o planejamento estratégico que define o objetivo a ser alcançado ("não se faz, né, só faz planejamento nosso mesmo, mas acho que não tem"). Acrescido do prazo para se obter os resultados esperados, é o que se denomina momento normativo do $\mathrm{PES}^{10}$.

As falas não evidenciam que a equipe trace um objetivo de modo participativo. Logo, não há sinergia entre gerente e técnicos para que todos se voltem à elaboração de uma meta única, pertinente a todos.

Sem plano de ação definido e um objetivo comum para a resolução de um problema, corre-se o risco de que, durante a análise da viabilidade do plano, considerado o momento estratégico do $\mathrm{PES}^{17,18}$, muitos sejam os conflitos a serem enfrentados ("então está assim, completamente desorganizado, mas é um problema que depende assim, de hierarquia, o coordenador fala e todo mundo fala a mesma língua"), levando-se em conta que é, nessa fase, em que se mapeiam os atores que podem cooperar ou se opor ao projeto ("porque não mandaram, o problema é esse, só faço o que me mandam" $)^{4}$.

É esperado, no momento estratégico do PES, que gerente e técnicos reforcem "o que fazer", "quem fará", "quando", "como", "onde", "com quem" e "com que recursos"10. Percebe-se que as unidades estudadas estão muito aquém de realizar um planejamento estratégico para quaisquer modificações no serviço que se queira implantar, pois as etapas básicas de um planejamento estratégico estão sendo negligenciadas.

O cenário estabelecido nas unidades não é favorável e, pelo fato de os dados provenientes das ações de saúde realizadas não serem transformados em informações (quando o são, as informações obtidas não contam com uma avaliação técnica e formal, mesmo que houvesse um objetivo comum), o processo comunicativo vigente não daria conta de que as ideias relacionadas ao projeto fossem transmitidas para os atores sociais envolvidos, no intuito de que pudessem percebê-las e se situarem perante suas responsabilidades.

Por último, há o momento tático-operacional, o qual corresponde à programação de curto prazo e inclui a tomada de decisão, controle e avaliação $0^{17,18}$. Assumir essa proposta estratégica de planejamento pode ser uma forma de construir um novo modo de pensar que supere a rotina e a inércia burocrática ${ }^{10}$.
De modo geral, gerentes e técnicos das unidades de saúde planejam suas atividades informalmente e, via de regra, pelo senso comum. Os resultados de suas ações nem sempre geram os resultados esperados, por isso é frequente a estratégia da "tentativa e erro" ("quando a gente percebeu que as pessoas estavam buscando a intercorrência para passar em consulta médica, a gente chegou num consenso nas reuniões de equipe. A gente estipula cinco, no final ele não deixa de atender ninguém”). Não há, portanto, predomínio do pensamento estratégico para a execução dos planos.

Estes não são baseados em uma prioridade que corresponda à realidade local, mas por normas técnicas comuns a todos os serviços, geralmente, diretrizes do Ministério da Saúde. Tais planos originam-se de objetivos elaborados ora pela gerência centralizadora, ora pelo acordo casual e cordial entre os integrantes da equipe, os quais tendem a ser mais comprometidos com a hierarquia do que com o alcance de uma meta.

Como as mudanças no processo de trabalho não resultaram de um planejamento estratégico, não é sem motivo que predominam as seguintes falas: "a bagunça está institucionalizada"; "sem perspectiva pra mim"; "que se lasque, a população vai se acostumando"; "não tem organização".

Para modificar esse cenário, é preciso que a instituição dê ênfase ao processo de aprendizagem, pois é a partir dele que a pessoa pode aprender a perceber ou a reinterpretar uma situação, aprender como aplicar essa percepção para a formulação de uma ação e aprender como implementar as ações pretendidas ${ }^{20}$.

Finalizando, a análise dos resultados obtidos por meio dos discursos dos atores sociais das USF de Pindamonhangaba não leva a crer que a condução da demanda espontânea que acessa os serviços de saúde esteja contemplada no PES, mesmo porque este não é realizado em nenhuma das unidades estudadas.

\section{Conclusão}

Conclui-se que não utilizar o planejamento estratégico para resolver os problemas da unidade pode gerar outros problemas: baixa qualidade na assistência sob a ótica do usuário, desgaste da equipe e do gerente, excesso de reclamações, divergências entre o que a equipe e o usuário consideram importantes e, para o caso da condução da demanda espontânea, a crença de que a manutenção da inércia local dê conta da acessibilidade para toda a população que é de direito e garantida em lei.

Acredita-se que, num ambiente em que o processo de trabalho é fragmentado, onde as rotinas não são revisadas, a comunicação é ineficaz, os registros não garantem informações, 
os planos não são fundamentados em prioridades e em objetivos claros e a gerência é inexpressiva, cabe ao órgão central, ou seja, à Diretoria de Saúde, providenciar um espaço para educação permanente de seus recursos humanos, sob o risco de inviabilizar a superação do modelo de assistência tradicional, em detrimento ao que se almeja pela Estratégia Saúde da Família na Atenção Básica à Saúde.

A linha mestra da educação permanente deve basear-se na reinterpretação das situações vivenciadas por todos os atores do PSF de Pindamonhangaba, de modo que seja possível aprender a implementar ações com novas maneiras de se trabalhar, ao invés das velhas atividades rotineiras.

É imprescindível que os gerentes sejam o foco da capacitação no que se refere a reverter o pensamento comum para o pensamento estratégico, uma vez que é por meio da construção de habilidades gerenciais que se espera resolver os problemas que afligem o cotidiano dos demais profissionais e usuários que acessam os serviços de saúde.

\section{Referências}

1. Poli P, Norman AH. Acolhimento e (des) medicalização: reflexões sobre essa prática em um Centro de Saúde. $8^{\circ}$ Congresso Brasileiro de Medicina de Família e Comunidade e $2^{\circ}$ Encontro Luso-brasileiro de Medicina Geral, Familiar e Comunitária; 2006; São Paulo. São Paulo: Sociedade Brasileira de Medicina de Família e Comunidade; 2006. p. 246.

2. Campinas LLSL. O acolhimento ao doente com tuberculose: estudo comparativo entre uma unidade de saúde da família e um ambulatório de especialidades médicas [Tese]. São Paulo: Faculdade de Saúde Pública da Universidade de São Paulo; 2003.

3. Fracolli LA, Bertolozzi MR. A abordagem do processo saúde-doença das famílias e do coletivo. In: Brasil. Instituto para o Desenvolvimento da Saúde. Universidade de São Paulo. Ministério da Saúde. Manual de Enfermagem: Programa Saúde da Família. São Paulo: Ministério da Saúde; 2001. p. 4-8.

4. Silva RMV, Fracolli LA, Zoboli ELCP. O acolhimento no PSF: da proposta teórica para a operacionalização na prática. Saúde e Sociedade. 2005; 14 Supl. 1: 245-6.

5. Pereira JG, Fracolli LA. Acolhimento e reorganização das práticas em saúde. Saúde e Sociedade. 2005; 14 Supl 1. p. 23

6. Pinheiro R. As práticas do cotidiano na relação oferta e demanda dos serviços de saúde: um campo de estudo e construção da integralidade. In: Pinheiro R, Mattos RA organizadores. Os sentidos da integralidade na atenção e no cuidado à saúde. Rio de Janeiro: IMS-UERJ; 2001. p. 65112

7. Gomes MCPA, Pinheiro R. Acolhimento e vínculo: práticas de integralidade na gestão do cuidado em saúde em grandes centros urbanos. Interface - Comunic, Saúde, Educ. 2005; 9(17): 287-301 doi: 10.1590/S141432832005000200006

8. Wolcott HF. Transforming qualitative data: description, analysis, and interpretation. Londres: Sage Publication; 1994.

9. Ciampone MHT, Peduzzi M. Planejamento Estratégico como instrumento de gestão e assistência. In: Brasil. Instituto para o Desenvolvimento da Saúde. Universidade de São Paulo. Ministério da Saúde. Manual de Enfermagem: Programa Saúde da Família. São Paulo; 2001. p. 23-28.

10. Kamimura QP. Microrregionalização: uma proposta metodológica, organizacional e estratégica para os serviços de saúde de alta e médica complexidade no Litoral Norte Paulista. [Dissertação]. Taubaté: Universidade de Taubaté; 2004

11. Rocha PM. Avaliando a qualidade em Atenção Primária em Saúde. Rev Bras Med Fam e Com. 2006; 1(4): 132-140.
12. Minayo MCS, Assis, SG, Souza ER. Avaliação por triangulação de métodos: abordagem de programas sociais. Rio de Janeiro: Fiocruz; 2005.

13. Minayo MCS. Conceito de avaliação por triangulação de métodos. In: Minayo MCS, Assis SG, Souza ER. Avaliação por triangulação de métodos: abordagem de programas sociais. Rio de Janeiro: Fiocruz; 2005. p. 1951.

14. Gomes R, et al. Organização, processamento, análise e interpretação de dados: o desafio da triangulação. In: Minayo MCS, Assis SG, Souza ER, organizadores. Avaliação por triangulação de métodos: abordagem de programas sociais. Rio de Janeiro: Fiocruz; 2005. p. 185-221.

15. Bardin L. Análise de Conteúdo. Lisboa: Edições 70; 1979.

16. Santana ML. Demanda espontânea e Planejamento Estratégico Situacional no Programa Saúde da Família de Pindamonhangaba. [Dissertação]. Taubaté: Universidade de Taubaté; 2008.

17. Matus C. Fundamentos da planificação situacional e os métodos do VII Plano da Nação. In: Rivera FJU, organizador. Planejamento e programação em saúde: um enfoque estratégico. São Paulo: Cortez/ABRASCO; 1989. p. 107-149.

18. Lana FCF, Gomes ELR. Reflexões sobre o planejamento em saúde e o processo da reforma sanitária brasileira. Rev Latinoam Enferm. 1996; 4(1) 97-110.

19. Brasil. Ministério da Saúde. Política Nacional de Atenção Básica. Brasília: Ministério da Saúde; 2006

20. Uribe FJ. Reflexões sobre a subjetividade na gestão a partir do paradigma da organização que aprende. Ciênc saúde coletiva. 2001; 6(1): 209-19 doi: 10.1590/S1413-81232001000100017

21. Meyer CA. Planejamento formal e seus resultados: um estudo de caso. Caderno de Pesquisas em Administração. 1997; 2(5): 39-46.

22. Brasil. Ministério da Saúde [Internet]. Programa Saúde da Família. [acesso em 7 maio 2006]. Disponível em: http://www.saude.gov.br

23. Carvalho AO, Paula Eduardo MB. Sistemas de Informação em Saúde para Municípios. São Paulo: Faculdade de Saúde Pública da Universidade de São Paulo; 1998

24. Bourget Ir MMM, organizador. Programa Saúde da Família: guia para o planejamento local. Coleção O Cotidiano do PSF. São Paulo: Martinari; 2005.

25. Vanderlei MIG,. O gerenciamento na estratégia da saúde da família: o processo de trabalho dos gestores e dos gerentes municipais de saúde em municípios do estado do Maranhão. [Tese]. São Paulo: Universidade de São Paulo; 2005

26. Oliveira MRCT, Ituassu CT. Uma análise dos impactos do treinamento e desempenho de profissionais e gerentes. Encontro Nacional de PósGraduação em Administração; 2004; Curitiba. Curitiba: Associação Nacional de Pós Graduação e Pesquisa em Administração; 2004.

27. Malik AM, et al. Gestão de Recursos Humanos. São Paulo: Faculdade de Saúde Pública da Universidade de São Paulo; 1998.

28. Cianciarullo TI. Saúde da Família - Avaliação da nova estratégia assistencial no cenário das políticas públicas. In: Cianciarullo TI, Silva GTR, Cunha ICKO. Uma nova estratégia em foco: o Programa de Saúde da Família: identificando as suas características no cenário do SUS. São Paulo: Icone: 2005.

29. Friedrich DBC, Pierantoni CR. O trabalho das equipes da saúde família: um olhar sobre as dimensões organizativa do processo produtivo, políticoideológica e econômica em Juiz de Fora. Physis. 2006; 16(1): 83-97 doi: 10.1590/S0103-73312006000100006

30. Campos GWS. Um método para análise e co-gestão de coletivos. $3^{\mathrm{a}}$ ed. São Paulo: Hucitec; 2007.

31. Hossmann H, Lourenço DM. A elevada demanda de pacientes versus qualidade na atenção primária à saúde. $8^{\circ} \mathrm{Congresso} \mathrm{Brasileiro} \mathrm{de} \mathrm{Medicina}$ de Família e Comunidade e $2^{\circ}$ Encontro Luso-brasileiro de Medicina Geral, Familiar e Comunitária; 2006; São Paulo. São Paulo: Sociedade Brasileira de Medicina de Família e Comunidade; 2006. p. 195.

32. Doria SCB, Polidoro MA. Implementação do acolhimento resolutivo na unidade básica de saúde da família e pronto atendimento do Jardim Macedônia, São Paulo; II Mostra Nacional de Produção em Saúde da Família; 2004; Brasília. Brasília: Trabalhos premiados; 2004. p. 76-86.

33. Daft RL. Administração. São Paulo: Pioneira Thomson Learning; 2005

34. Artmann E, Azevedo CS, Castilho Sá M. Possibilidades de aplicação do enfoque estratégico de planejamento no nível local de saúde: análise comparada de duas experiências. Cad Saúde Públ. 1997; 13(4): 723-40 doi: 10.1590/S0102-311X1997000400015 